\title{
Effects of different doses of high-speed resistance training on physical performance and quality of life in older women: a randomized controlled trial
}

This article was published in the following Dove Press journal:

Clinical Interventions in Aging

13 December 2016

Number of times this article has been viewed

\section{Rodrigo Ramirez-Campillo, ${ }^{1-3}$ Daniela Diaz, ${ }^{4}$ Cristian Martinez-Salazar, ${ }^{5}$ Pablo Valdés-Badilla, ${ }^{6}$ Pedro Delgado-Floody, ${ }^{5}$ Guillermo Méndez-Rebolledo, ${ }^{7}$ Rodrigo Cañas-Jamet, ${ }^{8,9}$ Carlos Cristi-Montero, ${ }^{10}$ Antonio García-Hermoso," Carlos Celis-Morales, ${ }^{12}$ Jason Moran, ${ }^{13}$ Thomas W Buford, ${ }^{14}$ Leocadio Rodriguez-Mañas, ${ }^{15}$ Alicia M Alonso-Martinez, ${ }^{16}$ Mikel Izquierdo ${ }^{16}$}

'Department of Physical Activity Sciences, 2Laboratory of Measurement and Assessment in Sports, Research Nucleus in Health, Physical Activity and Sports, Universidad de Los Lagos, Osorno, ${ }^{3}$ Unit of Integrative Physiology, Laboratory of Exercise Sciences, MEDS Clinic, Santiago, Chile; ${ }^{4}$ School of Occupational Therapy, Faculty of Health, Universidad Santo Tomás, Osorno, ${ }^{5}$ Department of Physical Education, Sport and Recreation, Universidad de La Frontera, ${ }^{6}$ nstitute of Physical Activity and Health, Universidad Autónoma de Chile, Temuco, ${ }^{7}$ School of Kinesiology, Faculty of Health, University Santo Tomás ${ }^{8}{ }^{8}$. Tomas, Talca, 'Laboratory of Physiology, Departmen of Biological Sciences, Faculty of Biological Sciences,
Universidad Andres Bello, Viña del Mar, ' $S$ School of Kinesiology, Faculty of Medicine, Universidad Diego Portales, Santiago, ${ }^{\circ} \mathrm{IRyS}$ Group, Physical Education School, Pontificia Universidad Católica de Valparaíso, Valparaíso, "Laboratory of Physical Activity Sciences, Sport and Health, Faculty of Medical Sciences, Universidad de Santiago de Chile, USACH, Sciences, Universid Santiago, Chile, 'BHF Glasgow Cardiovascular Research Centre, Institute of Cardiovascular and Medical Sciences, University of Glasgow, Glasgow, ${ }^{13}$ Centre for Sports and Exercise Science, School of Biological Sciences, University of Essex, Colchester, UK; ${ }^{14}$ Department of Aging and Geriatric Research, Institute of Aging, University of Florida, College of Medicine, Gainesville, Florida USA; ${ }^{15}$ Division of Madrid, ${ }^{16}$ Department of Health Sciences, Public University of Navarre, Navarre, Spain

Correspondence: Mikel Izquierdo Department of Health Sciences, Public University of Navarre, Campus of Tudela, Av de Tarazona s/n, 31500 Tudela, Navarre, Spain

Tel +34948417876

Email mikel.izquierdo@gmail.com
Objective: This study aimed to compare the effects of two frequencies of high-speed resistance training (HSRT) on physical performance and quality of life of older women.

Methods: A total of 24 older women participated in a 12-week HSRT program composed of either two or three sessions/week (equated for volume and intensity). Women were randomized into three arms: a control group ( $\mathrm{CG}, \mathrm{n}=8)$, a resistance training group performing two sessions/ week (RT2, n=8), and a resistance training group performing three sessions/week (RT3, n=8). The training program for both experimental groups included exercises that required high-speed concentric muscle actions.

Results: No baseline differences were observed among groups. Compared with the CG, both training groups showed similar small to moderate improvements $(P<0.05)$ in muscle strength, power, functional performance, balance, and quality of life.

Conclusion: These results suggest that equated for volume and intensity, two and three training sessions/week of HSRT are equally effective for improving physical performance and quality of life of older women.

Keywords: aging, muscle strength, adaptation, frailty

\section{Introduction}

A worldwide trend toward an aging population is clear, with greater number of older women compared to men. Advanced age is associated with reduced muscle strength, power, balance, and functional performance, ${ }^{1}$ leading to reduced quality of life, increased risk of cardiovascular disease, all-cause mortality, ${ }^{2}$ poor daily activities performance, ${ }^{3-5}$ and increased risk of falling, ${ }^{6,7}$ which can increase the risk of fractures. ${ }^{8}$ High-speed resistance training (HSRT) has emerged as a key intervention strategy to counteract these problems. ${ }^{9-12}$ Moreover, HSRT programs might offer an older population important adaptive advantages over more traditional low-speed resistance training interventions, ${ }^{1,13,14}$ such as greater training efficiency, ${ }^{15}$ reduced detraining effects, ${ }^{16}$ and potentially clinically meaningful morphological and neural adaptations. ${ }^{16,17}$

Though the optimal dose of HSRT may be debated, it is important to consider practical barriers to high-frequency training, such as frequent interruptions caused by family obligations, fear, or physical limitations, ${ }^{14}$ especially among older women. In this context, a resistance training frequency of 2 days/week has been recommended for older women. ${ }^{18} \mathrm{~A}$ reduced training frequency might motivate a long-term physically active lifestyle ${ }^{19}$ and a more gradual training progression. ${ }^{20}$ However, although HSRT seems to be an adequate stimulus to improve physical functions in an older 
population with two supervised training sessions/week, ${ }^{5,15,21}$ it is unknown if a higher training frequency (ie, three sessions/ week) would induce greater improvements. Among traditional low-speed resistance training interventions, similar training-induced adaptations have been observed with two and three sessions/week, ${ }^{18,22}$ especially when training volume and intensity are equated..$^{23}$ Moreover, efficiency of training is higher with two training sessions/week compared to three training sessions/week. ${ }^{24}$

Therefore, we hypothesized that with equal intensity and volume, two and three sessions/week of HSRT could be equally effective to promote improvements in physical performance and quality of life of older women.

\section{Methods}

This study was conducted as a single-blind and randomized controlled trial in the Human Performance Laboratory of the University of Los Lagos. Institutional ethics approval was obtained from University of Los Lagos for this study and was adhered to the Declaration of Helsinki.

\section{Participants}

Sixty older women provided written informed consent to participate in this study. The inclusion criteria were 1) healthy by self-report (ie, completion of the revised physical activity readiness questionnaire for older adults $)^{25}$ and by medical examination, 2) not participating in resistance training for the last 6 months, and 3) free of medications affecting dependent variables (eg, conjugated estrogen and immune-suppressive drugs). Participants who meet the inclusion criteria were electronically (https:/www.randomizer.org) randomized by blocked-design into three arms: a control group (CG), a group that completed two HSRT sessions/week (RT2), and a group that completed three HSRT sessions/week (RT3). This procedure was established according to the "CONSORT" statement (http://www.consort-statement.org). A graphical description of the randomization process is illustrated in Figure 1. All participants were instructed to keep their habitual lifestyle (including eating habits) throughout the intervention. The physical activity level was measured at baseline as previously described ${ }^{26}$ and was expressed in metabolic equivalents (MET-min/week).

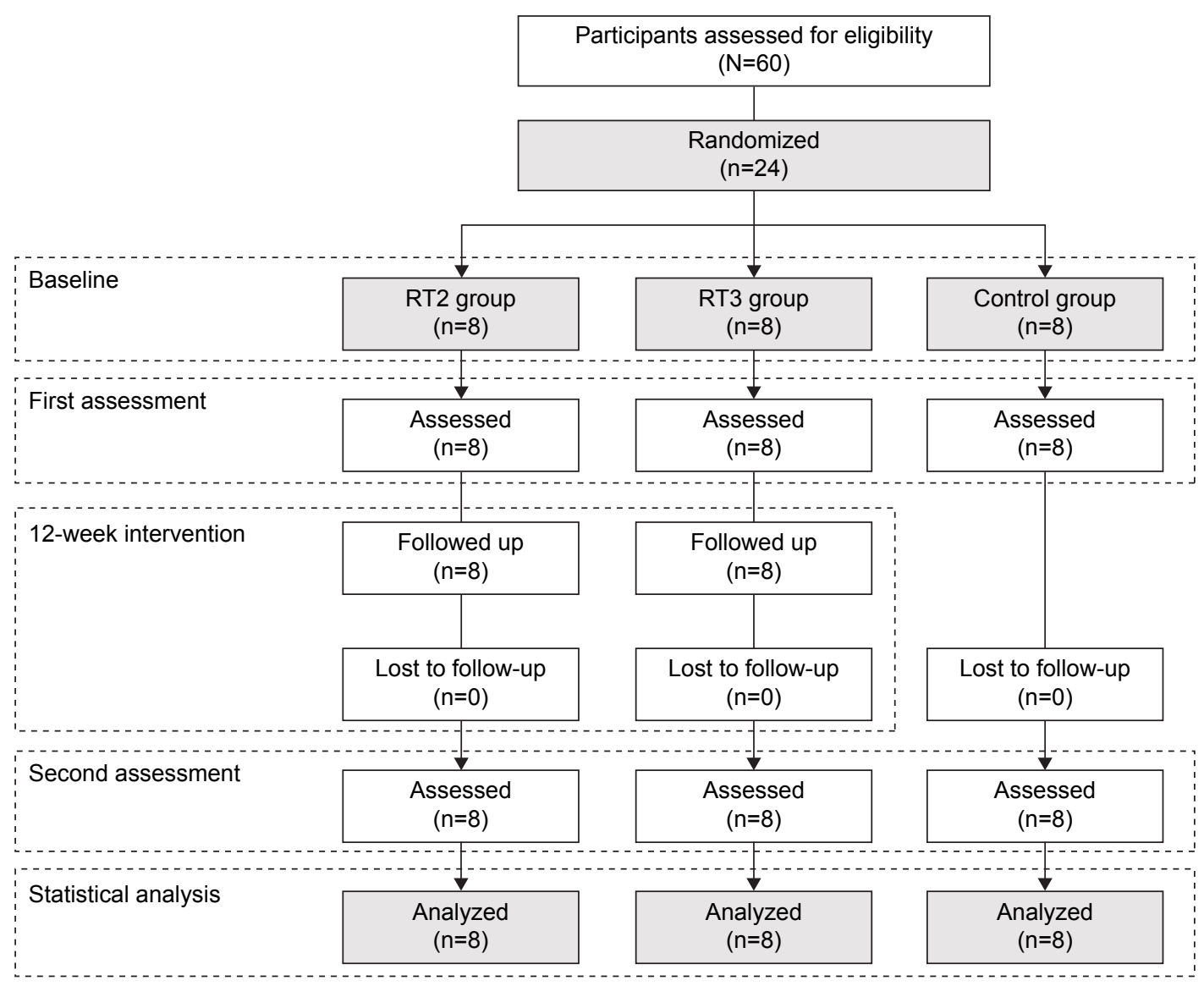

Figure I CONSORT diagram of recruitment and randomization process.

Abbreviations: RT2, resistance training group completing two training sessions/week; RT3, resistance training group completing three training sessions/week. 
The sample size was determined according to changes in lower limb peak muscle power performance (ie, leg press) of a group of older men and women assigned to a control ( $\Delta=-38 \mathrm{~W}$; standard deviation [SD] $=49$ ) or to a HSRT pro$\operatorname{gram}(\Delta=155 \mathrm{~W} ; \mathrm{SD}=25),{ }^{15}$ comparable with that applied in this study. The statistical power analysis indicated that eight participants per group would yield adequate power $(>80 \%)$ and $\alpha(0.05)$, with a detectable effect size of 0.2 .

\section{Testing procedures}

All measurements were applied using standardized protocols and trained staff (blinded to the training group of the participants). Participants followed a familiarization session of 90 minutes 1 week before measurements.

\section{Anthropometric and cardiovascular measures}

Height ( $\mathrm{m}$ ) and body mass ( $\mathrm{kg}$ ) were assessed using a stadiometer and calibrated scale (SECA, model 220, Hamburg, Germany) with precisions of $0.1 \mathrm{~cm}$ and $0.1 \mathrm{~kg}$, respectively. Body mass index was calculated $\left(\mathrm{kg} \cdot \mathrm{m}^{-2}\right)$. Resting heart rate and blood pressure measurements were taken twice after 10 minutes rest (Omron Healthcare Inc., Vernon Hills, IL, USA), and the mean value was used for analysis. ${ }^{27}$

\section{Handgrip strength}

Maximum dominant (HGd) and non-dominant (HGnd) handgrip strengths were measured using a hand dynamometer (Baseline, Irvington, NY, USA). The women exerted a maximal grip while sitting on a chair in an erect position with a $90^{\circ}$ hip, knee, and elbow flexion position, the shoulder adducted and neutrally rotated, and the forearm in a neutral position. Three measures (with 1 minute of rest between) of each hand were taken with the best result chosen for analysis.

\section{Medicine ball throwing}

Using a 2-kg medicine ball, throwing distance performance (BT) was measured. The women sat on a chair with their posterior trunk region positioned against the chair back and held the ball in front of them with both hands. Then, they were instructed to throw the ball as far and as fast as possible, using a throwing angle of $\sim 50^{\circ} \mathrm{C}$. Three attempts were made with 1 minute of rest between them. The best result was chosen for analysis.

\section{Ten meters walking sprint}

Participants were instructed to perform walking sprints of $10 \mathrm{~m}$ (S10). The sprint time was measured to the nearest 0.01 seconds using single-beam infrared photoelectric cells
(Ergotester, Globus, Codogne, Italy). The starting position was standardized to a still split standing position with the toe of the preferred foot forward and behind the starting line. Participants performed three maximum-effort trials, separated by 3 minutes of rest, on an indoor track. The best result was chosen for analysis.

\section{8-Foot up-and-go test (UG)}

The test consisted of standing up from a chair, walking $2.44 \mathrm{~m}$, turning, and returning to the initial seated position. The test was administered according to previously described instructions. ${ }^{12}$ Participants performed three trials, with 3 minutes of rest between them, on an indoor track. The best result was chosen for analysis.

\section{Sit-to-stand test (STS)}

The test consisted of standing up from a chair and returning to the initial seated position, completing as many repetitions as possible in 30 seconds. The test was administered according to previously described instructions. ${ }^{28}$ Participants performed two trials, with at least 4 minutes of rest between them. The best result was chosen for analysis.

\section{Bilateral balance}

Following previous recommendation $\mathrm{s}^{29}$ participants completed four stability tests performed on a balance platform at a sample rate of $1,000 \mathrm{~Hz}$ (Bertec BP5050 balance plate platform; Bertec Corporation, Columbus, OH, USA): 1) normal stance, eyes open; 2) normal stance, eyes closed; 3 ) perturbed stance, eyes open; and 4) perturbed stance, eyes closed. The perturbed stance condition was defined as that obtained while standing on a $3-\mathrm{cm}$ thick piece of foam. The average of four balance trials for each test was used for subsequent analysis and was expressed in centimeters. Both anterior-posterior and medial-lateral data were collected during each trial.

Quality of life - the menopause-specific quality of life questionnaire (MENQOL)

The MENQOL has thirty questions, divided into four areas of well-being: vasomotor, psychosocial, physical, and sexual. Each question explores the intensity of a perceived symptom, quantified with an integer rating scale between zero (no discomfort) and six (great discomfort). For scoring purposes, if the participant had no symptom for a question, then her score was one. If a participant had a symptom with a rating of zero, then her score was two and so on; for a maximum score of eight, the participant would declare a symptom with a rating of six. The total score for each area was used for 
analysis, with a greater score indicating worse quality of life and score reduction (negative $\Delta$ values) after intervention indicating improvements in quality of life. The MENQOL was preferred among other questionnaires due to its widespread use and established reliability and validity among menopausal women. ${ }^{30}$ In addition, participants completed the Spanish version of the questionnaire validated for Chilean women. ${ }^{31}$

\section{High-speed resistance training protocol}

Intervention lasted 12-weeks and was undertaken two (RT2) or three (RT3) times/week. Training was based on a previous effective and safe intervention. ${ }^{12}$ To equate training loads due to differences in the training frequency, the RT2 group completed three sets/exercise/session, whereas the RT3 completed two. After warm-up, the participants completed six throwing repetitions with a $2-\mathrm{kg}$ medicine ball and four repetitions of countermovement jump per set. Then, the participants completed four resistance-training exercises (ie, bench press, upright row, biceps curl, and leg extension), using eight repetitions/set at $75 \%$ of their baseline one repetition maximum (1RM). Baseline 1RM was established according to previous recommendations. ${ }^{12}$ All repetitions were completed using a concentric muscle action as fast as possible and an eccentric muscle action of 3 seconds (metronome-controlled). Using progressive overload, the resistance was increased $\sim 1 \%$ to $5 \%$ after participants were able to perform more than eight repetitions in their last set. After the resistance-training exercises, the participants performed 3 seconds of an intentional high-speed isometric squat/set. Then, participants performed 12-repetitions/set of the modified abdominal crunch and the prone superman exercise (ie, the last two with the aim to target core stabilizers), using a concentric and eccentric muscle action for 3 seconds each, respectively. Approximately 1 minute of rest was used between all sets. Sessions concluded with a cool down. A typical training session lasted 50 and 70 minutes for the RT3 and RT2 groups, respectively. Intervention sessions were always performed under the direct supervision of the same graduated exercise professionals. No injuries occurred during intervention and special care was taken to maintain equal intensity, volume, and attendance between RT2 and RT3.

\section{Statistical analysis}

Statistical analyses were performed with STATISTICA (Version 8.0; StatSoft, Inc., Tulsa, OK, USA). All values are reported as the mean $\pm \mathrm{SD}$. Relative changes $(\%)$ in the dependent variables and Cohen's $d$ effect sizes (ES) were expressed with $90 \%$ confidence limits (CLs), as previously suggested. ${ }^{32}$ Normality and homoscedasticity assumptions for all of the data before and after intervention were respectively checked with the Shapiro-Wilk and Levene's tests. The intervention-related effects were assessed using a two-way repeated measures analysis of variance (ANOVA) with factors: groups (3 levels) and time (2 levels), with Tukey's post hoc. One-way ANOVA was performed to detect changes between groups (ie, the differences between scores before and after the intervention). The $\alpha$ level was set at $P<0.05$ for statistical significance. The threshold values for assessing ES were $0.20,0.60,1.2$, and 2.0 for small, moderate, large, and very large, respectively. ${ }^{32}$ If the confidence interval overlapped thresholds for substantial positive and negative values, the effect was deemed unclear (ie, trivial). The effect was otherwise clear and reported as the magnitude of the observed value with a qualitative probability as noted above (ie, small, moderate, large, and very large). ${ }^{32}$ Due to the nature of this study, to equate the training volume between the RT2 and RT3 groups, only women who completed all training and evaluation sessions were included in the final analysis. The intraclass correlation coefficient (ICC) and the coefficient of variation $(\mathrm{CV})$ were used to test reliability for the physical performance measurements, with ICC values ranging from 0.81 to 0.98 and $\mathrm{CV}$ values from $1.6 \%$ to $6.4 \%$.

\section{Results}

At baseline no differences were observed in the descriptive variables among the $\mathrm{CG}(\mathrm{n}=8$; age $=68.9 \pm 7.5$ years; age range $=60-83$ years; number of daily medications $=1.6 \pm 0.7$; physical activity level =1,333 \pm 556 MET-min week $^{-1}$ ), the RT2 group $(n=8$; age $=70.0 \pm 6.9$ years; age range $=60-80$ years; number of daily medications $=1.5 \pm 0.5$; physical activity level $=1,435 \pm 523$ MET-min week $^{-1}$ ), and the RT3 group $(n=8$; age $=71.9 \pm 6.3$ years, age range $=62-78$ years; number of daily medications $=1.8 \pm 0.7$; physical activity level $=1,218 \pm 723$ MET-min week ${ }^{-1}$ ) or in the dependent variables (Tables 1-4).

No changes in body mass, height, body mass index, resting heart rate, and systolic and diastolic blood pressure were observed between pre- and post-intervention in either group.

While the CG showed no change from pre- to post-intervention, both RT2 and RT3 showed similar improvements in the dominant maximum isometric handgrip $(P<0.001$, $\mathrm{ES}=0.32 ; P<0.001, \mathrm{ES}=0.39$, respectively), non-dominant maximum isometric handgrip $(P<0.001, \mathrm{ES}=0.80$; $P<0.001, \mathrm{ES}=1.06$, respectively), ball throwing $(P<0.001$, $\mathrm{ES}=0.59 ; P<0.001, \mathrm{ES}=0.72$, respectively), 10-m walking sprint $(P<0.001, \mathrm{ES}=-0.38 ; P<0.01,-0.36$, respectively $)$, 
Table I Cohort characteristic at baseline of the intervention group

\begin{tabular}{|c|c|c|c|c|}
\hline Dependent variables & $\begin{array}{l}\text { CG } \\
(n=8)\end{array}$ & $\begin{array}{l}\text { RT2 } \\
(n=8)\end{array}$ & $\begin{array}{l}\text { RT3 } \\
(n=8)\end{array}$ & $P$-value \\
\hline Body mass (kg) & $59.6 \pm 7.2$ & $62.1 \pm 7.8$ & $64.7 \pm 6.5$ & 0.376 \\
\hline Height (cm) & $148 \pm 5.8$ & $149 \pm 4 . \mid$ & $148 \pm 6.5$ & 0.895 \\
\hline Body mass index $\left(\mathrm{kg} \cdot \mathrm{m}^{-2}\right)$ & $27.4 \pm 4.0$ & $28.0 \pm 4.1$ & $29.6 \pm 3.4$ & 0.505 \\
\hline $\begin{array}{l}\text { Resting heart rate (beats } \\
\min ^{-1} \text { ) }\end{array}$ & $70.3 \pm 7.1$ & $69.4 \pm 6.7$ & $73.0 \pm 10.3$ & 0.657 \\
\hline $\begin{array}{l}\text { Systolic blood } \\
\text { pressure }(\mathrm{mmHg})\end{array}$ & $146 \pm \mid 4.8$ & $156 \pm 18.1$ & $154 \pm 20.2$ & 0.151 \\
\hline $\begin{array}{l}\text { Diastolic blood } \\
\text { pressure }(\mathrm{mmHg})\end{array}$ & $76.8 \pm 7.3$ & $76.4 \pm 5.8$ & $74.9 \pm 7.9$ & 0.855 \\
\hline
\end{tabular}

Notes: Data are presented as mean \pm standard deviation. Differences between groups were investigated using one-way ANOVA test.

Abbreviations: ANOVA, analysis of variance; CG, control group; RT2, resistance training group completing two training sessions/week; RT3, resistance training group completing three training sessions/week.

8-foot up-and-go $(P<0.01, \mathrm{ES}=-0.48 ; P<0.001, \mathrm{ES}=-0.38$, respectively), and sit-to-stand tests $(P<0.001, \mathrm{ES}=1.12$; $P<0.001, \mathrm{ES}=0.64$, respectively). Improvements were greater compared with those of the CG (Table 2) for dominant maximum isometric handgrip (F2,21=9.17, $P<0.01)$,

Table 2 Training effects (with $90 \%$ confidence limits) for the strength, power-related, and functional performance variables

\begin{tabular}{|c|c|c|c|}
\hline $\begin{array}{l}\text { Dependent } \\
\text { variables }\end{array}$ & $\begin{array}{l}\text { Baseline, } \\
\text { mean } \pm \text { SD }\end{array}$ & Change (\%) & $\begin{array}{l}\text { Cohen's d } \\
\text { effect size }\end{array}$ \\
\hline \multicolumn{4}{|c|}{ Dominant maximum isometric handgrip (kg) } \\
\hline CG & $23.1 \pm 4.0$ & $1.3(-0.6,3.2)$ & $0.06(-0.03,0.16)$ \\
\hline RT2 & $22.2 \pm 5.9$ & $9.4(5.4,13.6)^{\mathrm{c}, \mathrm{e}}$ & $0.32(0.19,0.45)^{*}$ \\
\hline RT3 & $22.0 \pm 3.6$ & $8.4(6.5,10.3)^{\mathrm{c}, \mathrm{e}}$ & $0.39(0.30,0.47)^{*}$ \\
\hline \multicolumn{4}{|c|}{ Non-dominant maximum isometric handgrip (kg) } \\
\hline CG & $20.9 \pm 5.1$ & I.3 $(-1.5,4.2)$ & $0.04(-0.05,0.14)$ \\
\hline RT2 & $18.1 \pm 3.9$ & $23.4(17.5,29.6)^{\mathrm{ce}}$ & $0.80(0.61,0.98)^{* *}$ \\
\hline RT3 & $20.1 \pm 2.8$ & $19.4(11.9,27.3)^{\mathrm{c}, \mathrm{e}}$ & $1.06(0.67,1.44)^{* *}$ \\
\hline \multicolumn{4}{|c|}{ Ball throwing (cm) } \\
\hline CG & $248 \pm 33.5$ & $-2.1(-4.8,0.6)$ & $-0.14(-0.32,0.04)$ \\
\hline RT2 & $219 \pm 62.0$ & $19.1(8.0,31.3)^{\mathrm{c}, \mathrm{f}}$ & $0.59(0.26,0.92)^{*}$ \\
\hline RT3 & $231 \pm 46.3$ & $15.4(9.2,21.9)^{\mathrm{cff}}$ & $0.72(0.44,0.99)^{* *}$ \\
\hline \multicolumn{4}{|c|}{ I0-m walking sprint (s) } \\
\hline CG & $5.04 \pm 5.9$ & $2.2(-0.7,5.3)$ & $0.11(-0.04,0.25)$ \\
\hline RT2 & $5.71 \pm 1.2$ & $-9.3(-13.7,-4.6)^{\mathrm{c}, \mathrm{d}}$ & $-0.38(-0.58,-0.18)^{*}$ \\
\hline RT3 & $5.13 \pm 1.1$ & $-8.4(-10.8,-5.9)^{\mathrm{a}, \mathrm{f}}$ & $-0.36(-0.47,-0.25)^{*}$ \\
\hline \multicolumn{4}{|c|}{ 8-Foot up-and-go test (s) } \\
\hline CG & $6.96 \pm 0.9$ & $0.1(-3.0,3.2)$ & $0.01(-0.20,0.21)$ \\
\hline RT2 & $6.60 \pm 1.4$ & $-10.0(-13.4,-6.4)^{\mathrm{b}, \mathrm{e}}$ & $-0.48(-0.66,-0.30)^{*}$ \\
\hline RT3 & $7.10 \pm 1.9$ & $-10.2(-14.5,-5.7)^{\mathrm{c}, \mathrm{e}}$ & $-0.38(-0.55,-0.21)^{*}$ \\
\hline \multicolumn{4}{|c|}{ Sit-to-stand test (repetitions) } \\
\hline CG & $12.3 \pm 2.6$ & $-2.1(-10.5,7.2)$ & $-0.08(-0.40,0.25)$ \\
\hline RT2 & $15.3 \pm 2.6$ & $23.5(16.0,31.5)^{c, f}$ & I.I $12(0.79, \text { I. } .45)^{* *}$ \\
\hline RT3 & $12.5 \pm 3.5$ & $27.3(17.8,37.6)^{c, f}$ & $0.64(0.44,0.85)^{* *}$ \\
\hline
\end{tabular}

Notes: *Small; **moderate; a,b,csignificant difference (two-way ANOVA) from preto post-training $(P<0.05, P<0.01$, and $P<0.00$ I, respectively); d,e,fsignificant change in difference (one-way ANOVA) with the CG $(P<0.05, P<0.01$, and $P<0.00$ I, respectively)

Abbreviations: ANOVA, analysis of variance; CG, control group; RT2, resistance training group completing two training sessions/week; RT3, resistance training group completing three training sessions/week; SD, standard deviation.
Table 3 Training effects (with $90 \%$ confidence limits) for the balance performance variables

\begin{tabular}{|c|c|c|c|}
\hline $\begin{array}{l}\text { Dependent } \\
\text { variables }\end{array}$ & $\begin{array}{l}\text { Baseline, } \\
\text { mean } \pm \text { SD }\end{array}$ & Change (\%) & $\begin{array}{l}\text { Cohen's d } \\
\text { effect size }\end{array}$ \\
\hline \multicolumn{4}{|c|}{ Anterior-posterior normal stance eyes open $(\mathrm{cm})$} \\
\hline CG & $0.74 \pm 0.17$ & $2.1(-10.1,15.9)$ & $0.08(-0.39,0.54)$ \\
\hline RT2 & $0.70 \pm 0.24$ & $-17.0(-24.0,-9.5)^{\mathrm{a}, \mathrm{b}}$ & $-0.46(-0.68,-0.25)^{*}$ \\
\hline RT3 & $0.79 \pm 0.28$ & $-18.8(-24.3,-12.9)^{\mathrm{a}, \mathrm{b}}$ & $-0.55(-0.73,-0.36)^{*}$ \\
\hline \multicolumn{4}{|c|}{ Medial-lateral normal stance eyes open $(\mathrm{cm})$} \\
\hline CG & $0.60 \pm 0.15$ & $7.7(-2.6,19.0)$ & $0.27(-0.10,0.64)^{*}$ \\
\hline RT2 & $0.61 \pm 0.19$ & $-15.9(-23.3,-7.8)^{\mathrm{c,d}}$ & $-0.49(-0.75,-0.23)^{*}$ \\
\hline RT3 & $0.63 \pm 0.20$ & $-15.7(-19.2,-12.0)^{\mathrm{a}, \mathrm{d}}$ & $-0.49(-0.61,-0.37)^{*}$ \\
\hline \multicolumn{4}{|c|}{ Anterior-posterior normal stance eyes closed $(\mathrm{cm})$} \\
\hline CG & $0.97 \pm 0.17$ & $-2.8(-9.1,3.9)$ & $-0.13(-0.42,0.17)$ \\
\hline RT2 & $0.96 \pm 0.27$ & $-23.0(-32.3,-12.4)^{\mathrm{d}, \mathrm{e}}$ & e $-0.68(-1.01,-0.34)^{* *}$ \\
\hline RT3 & $1.10 \pm 0.33$ & $-25.1(-31.7,-17.9)^{\mathrm{e}, \mathrm{f}}$ & $-0.95(-1.25,-0.65)^{* *}$ \\
\hline \multicolumn{4}{|c|}{ Medial-lateral normal stance eyes closed $(\mathrm{cm})$} \\
\hline CG & $0.67 \pm 0.20$ & $16.9(5.2,29.9)^{\mathrm{a}}$ & $0.48(0.16,0.80)$ \\
\hline RT2 & $0.67 \pm 0.24$ & $-17.4(-23.7,-10.5)^{\mathrm{a}, \mathrm{f}}$ & $-0.5 \mathrm{I}(-0.72,-0.30)^{*}$ \\
\hline RT3 & $0.71 \pm 0.22$ & $-16.2(-21.3,-10.7)^{\mathrm{a}, \mathrm{f}}$ & $-0.60(-0.82,-0.38)^{* *}$ \\
\hline \multicolumn{4}{|c|}{ Anterior-posterior perturbed stance eyes open $(\mathrm{cm})$} \\
\hline CG & $0.88 \pm 0.21$ & $4.8(-4.5,15.0)$ & $0.16(-0.16,0.49)$ \\
\hline RT2 & $0.88 \pm 0.28$ & $-21.4(-34.3,-6.1)^{c, d}$ & $-0.47(-0.83,-0.12)^{*}$ \\
\hline RT3 & $0.92 \pm 0.33$ & $-15.2(-20.1,-10.0)^{\mathrm{a}, \mathrm{d}}$ & $-0.43(-0.59,-0.28)^{*}$ \\
\hline \multicolumn{4}{|c|}{ Medial-lateral perturbed stance eyes open $(\mathrm{cm})$} \\
\hline CG & $0.84 \pm 0.13$ & $0.3(-5.5,6.5)$ & $0.02(-0.32,0.35)$ \\
\hline RT2 & $0.88 \pm 0.18$ & $-15.6(-20.1,-10.9)^{e, d}$ & $-0.65(-0.86,-0.44)^{* *}$ \\
\hline RT3 & $0.91 \pm 0.25$ & $-15.2(-21.2,-8.7)^{\mathrm{e}, \mathrm{d}}$ & $-0.58(-0.84,-0.32)^{*}$ \\
\hline \multicolumn{4}{|c|}{ Anterior-posterior perturbed stance eyes closed $(\mathrm{cm})$} \\
\hline CG & $1.24 \pm 0.22$ & $0.2(-5.8,6.6)$ & $0.01(-0.34,0.37)$ \\
\hline RT2 & $1.21 \pm 0.26$ & $-15.5(-18.8,-12.0)^{e, f}$ & $-0.73(-0.90,-0.56)^{* *}$ \\
\hline RT3 & $1.25 \pm 0.40$ & $-15.9(-18.7,-13.0)^{e, f}$ & $-0.53(-0.64,-0.43)^{*}$ \\
\hline \multicolumn{4}{|c|}{ Medial-lateral perturbed stance eyes closed $(\mathrm{cm})$} \\
\hline CG & $0.91 \pm 0.18$ & $5.0(-4.6,15.6)$ & $0.20(-0.19,0.60)$ \\
\hline RT2 & $1.00 \pm 0.21$ & $-15.7(-18.5,-12.7)^{c, d}$ & $d-0.69(-0.83,-0.55)^{* *}$ \\
\hline RT3 & $1.02 \pm 0.24$ & $-14.6(-21.5,-7.1)^{c, d}$ & $-0.61(-0.94,-0.29)^{* *}$ \\
\hline
\end{tabular}

Notes: *Small; **moderate; a,c,esignificant difference (two-way ANOVA) from preto post-training $(P<0.05, P<0.0$ I, and $P<0.00$ I, respectively); b,d,significant change in difference (one-way ANOVA) with the CG $(P<0.05, P<0.01$, and $P<0.001$, respectively).

Abbreviations: ANOVA, analysis of variance; CG, control group; RT2, resistance training group completing two training sessions per week; RT3, resistance training group completing three training sessions per week.

non-dominant maximum isometric handgrip $(\mathrm{F} 2,21=12.87$, $P<0.001)$, ball throwing $(\mathrm{F} 2,21=14.60, P<0.001), 10 \mathrm{~m}$ walking sprint (F2,21=12.46, $P<0.001), 8$-foot up-and-go (F2,21=8.09, $P<0.01)$, and sit-to-stand tests (F2,21=17.69, $P<0.001)$.

Balance showed no change from pre- to post-intervention in the CG, except for the impaired medial-lateral normal stance with eyes closed balance test performance $(P<0.05$, ES $=0.48)$. In contrast, both the RT2 and the RT3 groups showed similar improvements in all balance tests (ES between -0.43 and -0.95$)$ for anterior-posterior normal stance eyes open $(P<0.05)$, medial-lateral normal stance eyes open $(P<0.01$ and $P<0.05$, respectively), anterior-posterior normal stance 
Table 4 Training effects (with $90 \%$ confidence limits) for the responses to the menopause-specific quality of life questionnaire

\begin{tabular}{|c|c|c|c|}
\hline $\begin{array}{l}\text { Dependent } \\
\text { variables }\end{array}$ & $\begin{array}{l}\text { Baseline, } \\
\text { mean } \pm \text { SD }\end{array}$ & Change (\%) & $\begin{array}{l}\text { Cohen's } d \text { effect } \\
\text { size }\end{array}$ \\
\hline \multicolumn{4}{|l|}{ Psychosocial } \\
\hline CG & $13.8 \pm 5.0$ & $3.2(-2.1,8.8)$ & $0.06(-0.04,0.17)$ \\
\hline RT2 & $14.5 \pm 10.5$ & $-22.3(-32.0,-11.3)^{\mathrm{a}, \mathrm{b}}$ & $-0.25(-0.38,-0.12)^{*}$ \\
\hline RT3 & $14.1 \pm 3.2$ & $-21.6(-31.5,-10.2)^{a, b}$ & $-0.4 \mathrm{I}(-0.64,-0.18)^{*}$ \\
\hline \multicolumn{4}{|l|}{ Physical } \\
\hline CG & $28.6 \pm 10.5$ & $4.6(-4.9,15.1)$ & $0.10(-0.12,0.32)$ \\
\hline RT2 & $36.5 \pm 16.7$ & $-42.1(-52.9,-28.8)^{\mathrm{b}, \mathrm{c}}$ & $-1.24(-1.71,-0.77)^{* * * *}$ \\
\hline RT3 & $37.6 \pm 20.3$ & $-51.7(-62.5,-37.7)^{\mathrm{c}, \mathrm{d}}$ & $-1.09(-1.47,-0.71)^{\text {** }}$ \\
\hline \multicolumn{4}{|l|}{ Overall } \\
\hline CG & $67.4 \pm 19.1$ & $3.6(-1.1,8.5)$ & $0.09(-0.03,0.21)$ \\
\hline RT2 & $79.0 \pm 31.1$ & $-22.1(-33.4,-8.9)^{\mathrm{a}, \mathrm{b}}$ & $-0.65(-1.06,-0.24)^{* * *}$ \\
\hline RT3 & $72.8 \pm 29.7$ & $-32.4(-40.8,-22.8)^{\mathrm{c}, \mathrm{b}}$ & $-0.81(-1.08,-0.53)^{\text {*** }}$ \\
\hline
\end{tabular}

Notes: *Small; **moderate; $* * *$ large; ${ }^{\text {acs significant difference (two-way ANOVA) }}$ from pre- to post-training $(P<0.05$ and $P<0.01$, respectively); b,dsignificant change in difference (one-way ANOVA) with the $C G(P<0.05$ and $P<0.01$, respectively). Abbreviations: ANOVA, analysis of variance; CG, control group; RT2, resistance training group completing two training sessions per week; RT3, resistance training group completing three training sessions per week; SD, standard deviation.

eyes closed $(P<0.001)$, medial-lateral normal stance eyes closed $(P<0.05)$, anterior-posterior perturbed stance eyes open $(P<0.01$ and $P<0.05$, respectively), medial-lateral perturbed stance eyes open $(P<0.001)$, anterior-posterior perturbed stance eyes closed $(P<0.001)$, and mediallateral perturbed stance eyes closed $(P<0.01)$. The improvements were greater compared with those of the CG (Table 3) for anterior-posterior normal stance eyes open (F2,21=9.80, $P<0.01)$, media-lateral normal stance eyes open $(\mathrm{F} 2,21=10.66, P<0.01)$, anterior-posterior normal stance eyes closed $(\mathrm{F} 2,21=5.40, P<0.05)$, medial-lateral normal stance eyes closed (F2,21=14.46, $P<0.001)$, anteriorposterior perturbed stance eyes open $(\mathrm{F} 2,21=9.78, P<0.01)$, medial-lateral perturbed stance eyes open $(\mathrm{F} 2,21=8.26$, $P<0.01)$, anterior-posterior perturbed stance eyes closed (F2,21=8.99, $P<0.01)$, and medial-lateral perturbed stance eyes closed $(\mathrm{F} 2,21=10.91, P<0.01)$.

For the CG, RT2, and RT3 groups, the vasomotor quality

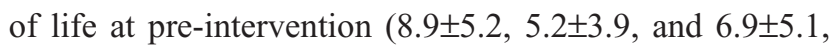
respectively) and sexual quality of life at pre-intervention

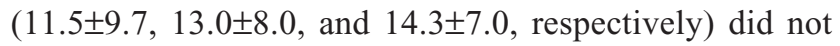
change post-intervention. Similarly, psychosocial, physical, and overall quality of life showed no change from pre- to post-intervention in the CG. In contrast, both the RT2 and the RT3 groups showed similar improvements in the psychosocial $(P<0.05, \mathrm{ES}=-0.25 ; P<0.05, \mathrm{ES}=-0.41$, respectively), physical $(P<0.01, \mathrm{ES}=-1.24 ; P<0.01, \mathrm{ES}=-1.29$, respectively), and overall quality of life $(P<0.05, \mathrm{ES}=-0.65$; $P<0.01,-0.81$, respectively), and the improvements were greater compared with those of the CG (Table 4) for psychosocial (F2,21=6.00, $P<0.01)$, physical $(\mathrm{F} 2,21=7.73$, $P<0.01)$, and overall quality of life (F2,21=5.54, $P<0.05)$.

\section{Discussion}

The main findings of study show that two or three HSRT sessions/week are equally effective for improving physical performance and quality of life of older women.

Early reports suggested that 18 weeks of traditional resistance training performed three times/week induced greater $(\sim 7.5 \%)$ isometric strength benefits compared with two times/week, ${ }^{24}$ although there was $50 \%$ less total training volume completed under the two times/week training modality. Moreover, training efficiency (performance percentage improvement/total number of sets) was higher with two $(0.58 \%$ per set $)$ compared to three $(0.53 \%$ per set $)$ training sessions/week. More recent studies demonstrated that when training volume is equated (as in the present study), two and three training sessions/week induced similar improvements ${ }^{23}$ or even greater training efficiency. ${ }^{22,33}$ Because in the present study the RT2 and RT3 groups had the same training volume and intensity, it is not surprising that both training groups achieved similar improvements. From a practical point of view, it should be considered that the participation routine of older women in training programs is usually interrupted (eg, family obligations, fear, and physical limitations). ${ }^{14}$ Therefore, the dose of training at a reduced frequency might optimize the time invested by older women into training. ${ }^{15,33}$ Moreover, a lower training frequency allows for a more gradual training progression, ${ }^{20}$ significantly reducing the inherent risk of adverse events during training progression, especially in older adults. ${ }^{34}$

Maximal strength was improved after HSRT, as in previous studies among older subjects. ${ }^{12,15,17}$ Because impairments of maximal strength have been extensively associated with declines in daily activities performance, ${ }^{35}$ low quality of life, ${ }^{36}$ and all-cause mortality among older subjects, ${ }^{2}$ our results have important practical, as well as clinical, implications.

A novel finding of this study was that power-related throwing performance is equally improved with two or three HSRT sessions/week. Because the muscle power of older women is closely associated with a risk of falling and functional and daily activities performance, ${ }^{3}$ it is imperative to help older women achieve adequate levels of muscle power and maintain them over time. As the reduced time investment from a lower training frequency might help to maintain a long-term physically active lifestyle, ${ }^{19}$ our results provide important information regarding a potential strategy to help 
women achieve and maintain an adequate muscle power level over time.

This is the first study to report similar improvements in walking, UG, and STS performance of older women after completing an equated dose of an HSRT program distributed under two or three training sessions/week. The improvements may suggest reduced neuromuscular wasting processes,${ }^{37}$ morphological and neural adaptations, ${ }^{17}$ and better survival. ${ }^{38}$

An equal improvement in balance after two and three HSRT sessions/week was observed. These novel results help us to better understand and optimize the balance-enhancing potential of HSRT for older women. Neuromuscular factors might help us to understand the improved eyes-opened and eyes-closed phases of balance performance after HSRT, such as enhanced force control, improved components of the neural pathway and function, reduced response latency, better recruitment of postural muscles, or improved interpretation of sensory information. ${ }^{39}$

Quality of life improved in both training groups. As muscle strength, ${ }^{12,36}$ power, ${ }^{12}$ and functional performance ${ }^{12,37}$ are associated with quality of life of older women, the improvements in these variables in both training groups may help to explain the quality of life improvements. Therefore, HSRT might be applied to counter physical performance decrements among older women, which might lead not only to reduced morbidity and mortality but also to better quality of life of older women.

A potential limitation of the study was the absence of more physiological measurements to better understand underlying mechanisms (eg, electromyographic activity) of HSRT-induced adaptations. In addition, physical activity levels should be measured during and after training intervention (not only at baseline), to detect its potential effects on dependent variables. Further studies are needed to clarify how different frequency may affect training-induced adaptations when a multicomponent exercise intervention program is incorporated, including HSRT. Moreover, further studies may aim to replicate current results with greater samples sizes of older women, including long-term follow-up.

\section{Conclusion}

In summary, two or three training sessions/week of HSRT (equated for volume and intensity) are equally effective for improving physical performance and quality of life of older women. These results may be of practical relevance in clinical contexts where older women have trouble to attend frequent training sessions.

\section{Acknowledgments}

The authors wish to thank all the participants who participated in this study. This work was supported by the Research Direction from University of Los Lagos, Internal Grant Program (grant number R03/15). This project is also funded in part by the European Commission (FP7-Health, Project reference 278803 ).

\section{Disclosure}

The authors report no conflicts of interest in this work.

\section{References}

1. Izquierdo M, Cadore EL. Muscle power training in the institutionalized frail: a new approach to counteracting functional declines and very late-life disability. Curr Med Res Opin. 2014;30(7): $1385-1390$

2. Ruiz JR, Sui X, Lobelo F, et al. Association between muscular strength and mortality in men: prospective cohort study. BMJ. 2008;337:a439.

3. Suzuki T, Bean JF, Fielding RA. Muscle power of the ankle flexors predicts functional performance in community-dwelling older women. J Am Geriatr Soc. 2001;49(9):1161-1167.

4. Casas-Herrero A, Cadore EL, Zambom-Ferraresi F, et al. Functional capacity, muscle fat infiltration, power output, and cognitive impairment in institutionalized frail oldest old. Rejuvenation Res. 2013;16(5): 396-403.

5. Cadore EL, Casas-Herrero A, Zambom-Ferraresi F, et al. Multicomponent exercises including muscle power training enhance muscle mass, power output, and functional outcomes in institutionalized frail nonagenarians. Age (Dordr). 2014;36(2):773-785.

6. Han L, Yang F. Strength or power, which is more important to prevent slip-related falls? Hum Mov Sci. 2015;44:192-200.

7. Rubenstein LZ. Falls in older people: epidemiology, risk factors and strategies for prevention. Age Ageing. 2006;35(Suppl 2):ii37-ii41.

8. Lips P. Epidemiology and predictors of fractures associated with osteoporosis. Am J Med. 1997;103(2A):3S-8S; discussion $8 \mathrm{~S}-11 \mathrm{~S}$.

9. Pereira A, Izquierdo M, Silva AJ, et al. Effects of high-speed power training on functional capacity and muscle performance in older women. Exp Gerontol. 2012;47(3):250-255.

10. Pereira A, Izquierdo M, Silva AJ, et al. Muscle performance and functional capacity retention in older women after high-speed power training cessation. Exp Gerontol. 2012;47(8):620-624.

11. Holviala JH, Sallinen JM, Kraemer WJ, Alen MJ, Hakkinen KK. Effects of strength training on muscle strength characteristics, functional capabilities, and balance in middle-aged and older women. $J$ Strength Cond Res. 2006;20(2):336-344.

12. Ramirez-Campillo R, Castillo A, de la Fuente CI, et al. High-speed resistance training is more effective than low-speed resistance training to increase functional capacity and muscle performance in older women. Exp Gerontol. 2014;58:51-57.

13. Porter MM. Power training for older adults. Appl Physiol Nutr Metab. 2006;31(2):87-94.

14. Marques MC, Izquierdo M, Pereira A. High-speed resistance training in elderly people: a new approach toward counteracting age-related functional capacity loss. Strength Con J. 2013;35(2):23-29.

15. Henwood TR, Riek S, Taaffe DR. Strength versus muscle power-specific resistance training in community-dwelling older adults. $J$ Gerontol $A$ Biol Sci Med Sci. 2008;63(1):83-91.

16. Hakkinen K, Alen M, Kallinen M, Newton RU, Kraemer WJ. Neuromuscular adaptation during prolonged strength training, detraining and re-strength-training in middle-aged and elderly people. Eur J Appl Physiol. 2000;83(1):51-62. 
17. Wallerstein LF, Tricoli V, Barroso R, et al. Effects of strength and power training on neuromuscular variables in older adults. J Aging Phys Act. 2012;20(2):171-185.

18. Chodzko-Zajko WJ, Proctor DN, Fiatarone Singh MA, et al. American College of Sports Medicine position stand. Exercise and physical activity for older adults. Med Sci Sports Exerc. 2009;41(7):1510-1530.

19. Gray PM, Murphy MH, Gallagher AM, Simpson EE. Motives and barriers to physical activity among older adults of different socio-economic status. J Aging Phys Act. 2016;24(3):419-429.

20. American College of Sports M. American College of Sports Medicine position stand. Progression models in resistance training for healthy adults. Med Sci Sports Exerc. 2009;41(3):687-708.

21. Caserotti P, Aagaard P, Larsen JB, Puggaard L. Explosive heavyresistance training in old and very old adults: changes in rapid muscle force, strength and power. Scand J Med Sci Sports. 2008;18(6): 773-782.

22. Fisher G, McCarthy JP, Zuckerman PA, Bryan DR, Bickel CS, Hunter GR. Frequency of combined resistance and aerobic training in older women. $J$ Strength Cond Res. 2013;27(7):1868-1876.

23. Candow DG, Burke DG. Effect of short-term equal-volume resistance training with different workout frequency on muscle mass and strength in untrained men and women. J Strength Cond Res. 2007; 21(1):204-207.

24. Braith RW, Graves JE, Pollock ML, Leggett SL, CarpenterDM, Colvin AB. Comparison of 2 vs 3 days/week of variable resistance training during 10- and 18-week programs. Int J Sports Med. 1989;10(6): $450-454$.

25. Cardinal BJ, Esters J, Cardinal MK. Evaluation of the revised physical activity readiness questionnaire in older adults. Med Sci Sports Exerc. 1996;28(4):468-472.

26. Ramirez-Campillo R, Martinez C, de La Fuente CI, et al. High-speed resistance training in older women: the role of supervision. J Aging Phys Act. 2016: Epub 2016 Aug 24.

27. Rossow LM, Fahs CA, Thiebaud RS, et al. Arterial stiffness and blood flow adaptations following eight weeks of resistance exercise training in young and older women. Exp Gerontol. 2014;53:48-56.

28. Hallage T, Krause MP, Haile L, et al. The effects of 12 weeks of step aerobics training on functional fitness of elderly women. J Strength Cond Res. 2010;24(8):2261-2266.
29. Bellew JW, Yates JW, Gater DR. The initial effects of low-volume strength training on balance in untrained older men and women. J Strength Cond Res. 2003;17(1):121-128.

30. Hilditch JR, Lewis J, Peter A, et al. A menopause-specific quality of life questionnaire: development and psychometric properties. Maturitas. 1996;24(3):161-175.

31. Blumel JE, Castelo-Branco C, Binfa L, et al. Quality of life after the menopause: a population study. Maturitas. 2000;34(1):17-23.

32. Hopkins WG, Marshall SW, Batterham AM, Hanin J. Progressive statistics for studies in sports medicine and exercise science. Med Sci Sports Exerc. 2009;41(1):3-13.

33. de Villarreal ES, Gonzalez-Badillo JJ, Izquierdo M. Low and moderate plyometric training frequency produces greater jumping and sprinting gains compared with high frequency. J Strength Cond Res. 2008;22(3):715-725

34. WHO. Global recommendations on physical activity for health. World Health Organization; 2010. Available from: http://apps.who.int/iris/bi tstream/10665/44399/1/9789241599979_eng.pdf. Accessed November $18,2016$.

35. Ensrud KE, Nevitt MC, Yunis C, et al. Correlates of impaired function in older women. J Am Geriatr Soc. 1994;42(5):481-489.

36. Benton MJ, Alexander JL, Holland JD. Relationship between strength, function, and quality of life in older adults with chronic lung disease: is there an influence of gender? J Cardiopulm Rehabil Prev. 2014;34(2):143-149.

37. Tseng BS, Marsh DR, Hamilton MT, Booth FW. Strength and aerobic training attenuate muscle wasting and improve resistance to the development of disability with aging. J Gerontol A Biol Sci Med Sci. 1995; 50 Spec No:113-119.

38. Studenski S, Perera S, Patel K, et al. Gait speed and survival in older adults. JAMA. 2011;305(1):50-58.

39. Orr R, de Vos NJ, Singh NA, Ross DA, Stavrinos TM, FiataroneSingh MA. Power training improves balance in healthy older adults. J Gerontol A Biol Sci Med Sci. 2006;61(1):78-85.
Clinical Interventions in Aging

\section{Publish your work in this journal}

Clinical Interventions in Aging is an international, peer-reviewed journal focusing on evidence-based reports on the value or lack thereof of treatments intended to prevent or delay the onset of maladaptive correlates of aging in human beings. This journal is indexed on PubMed Central, MedLine,

\section{Dovepress}

CAS, Scopus and the Elsevier Bibliographic databases. The manuscript management system is completely online and includes a very quick and fair peer-review system, which is all easy to use. Visit http://www.dovepress. com/testimonials.php to read real quotes from published authors. 